\title{
Study on the Conditions of Biogas Fermentation from Distillers' Grains
}

\author{
Mengmeng Yu, Qinghua Ding, Zhifeng Lv, Yuancheng Zhang* \\ Department of Technology Center, Shandong Bori Bioenergy Co., Ltd., Dongying, China \\ Email address: \\ 1170494675@qq.com (Mengmeng Yu),517080064@qq.com (Yuancheng Zhang) \\ ${ }^{*}$ Corresponding author
}

\section{To cite this article:}

Mengmeng Yu, Qinghua Ding, Zhifeng Lv, Yuancheng Zhang. Study on the Conditions of Biogas Fermentation from Distillers' Grains. International Journal of Oil, Gas and Coal Engineering. Vol. 7, No. 1, 2019, pp. 40-46. doi: 10.11648/j.ogce.20190701.17

Received: December 26, 2018; Accepted: January 25, 2019; Published: February 19, 2019

\begin{abstract}
The distillers' grains fermentation was studied, which was from ethanol fermentation of sweet sorghum stalk. The factors such as temperature, concentration, inocula, $\mathrm{pH}$ etc. were analysis. The results showed the optimal temperature was $55^{\circ} \mathrm{C}$, the optimal weight concentration of distillers' grains was $3.3 \%$, the amount of inocula was $1.5 \%$, and the $\mathrm{pH}$ should be adjusted before fermentation. Under this condition, the maximum biogas production was $3710 \mathrm{~mL} / \mathrm{d}$ and appeared in the 9th day. The overall length of the fermentation period was $32 \mathrm{~d}$, and the biogas production rate was up to $509 \mathrm{~mL} / \mathrm{gTS}$. The results could provide a theoretical basis for the fermentation of biogas production from distillers' grains.
\end{abstract}

Keywords: Distillers' Grains, Biogas, Fermentation

\section{Introduction}

At present, $85 \%$ energy is obtained through non-renewable mineral resources in the world. Due to the limited reserves of mineral resources and the increasing awareness of environmental protection, people began to seek new alternative resources [1-4]. Processing non-grain bioethanol with sweet sorghum stalk has many benefits for people. For example it can avoid competing for food with humans, land with grain, profits with traditional industries, and resources with other countries $[5,6]$. It has strategic significance to upgrade the future energy structure, ensure energy security and improve the living environment of human beings continuously [7]. However, it will produce a large number of distiller's grains with sweet sorghum stalk producing ethanol. If these distiller's grains are not stored properly or used in time, they are prone to mildew and deterioration, which not only waste valuable resources, but also seriously pollute the surrounding environment $[8,9]$.

Now China is short of energy, and the per capita natural gas resources is far lower than average level of the world [10-11]. If the distiller's grains came from bio-ethanol production are converted into renewable clean energy by biogas fermentation technology, it can solve the disposal problem of distiller grain in million tons, and the biogas can be directly used as household gas or generated electricity or produced vehicle fuel or injects natural gas network by further purification. The biogas fermentation residue can also be produced to organic fertilizers, which plays an important role in environment and land improvement [12-14]. This paper mainly study the effects of temperature, TS concentration of feedstock, $\mathrm{PH}$ and inocula concentration on biogas fermentation of distiller's grains which produced from sweet sorghum stalk after ethanol production. It can provide some theoretical basis for related production enterprises to make full use of distiller's grains $[15,16]$.

\section{Material and Method}

\subsection{Experiment Material}

The residue of distiller's grains after solid state fermentation to produce ethanol with sweet sorghum straw as raw material are provided by Shandong Bori Bioenergy Co., Ltd.

Biogas liquid in biogas tank with corn straw as raw material for experiment at $48^{\circ} \mathrm{C}$ are supplied by Shandong Bori Bioenergy Co., Ltd.

The sodium hydroxide solution at $1 \mathrm{M}(\mathrm{mol})$ concentration was used to adjust the $\mathrm{pH}$ of the substrate. The properties of various materials are shown in Table 1. 
Table 1. Basic properties of raw materials.

\begin{tabular}{llllllll}
\hline Material & TS\% & VS\% & C\% & N\% & C/N & organic matter \% & fibrin\% \\
\hline distillers' grains & 16.55 & 15.36 & 7.32 & 0.31 & 24 & 12.45 & 6.37 \\
inoculums & 7.20 & 3.34 & 1.6 & 0.22 & 7 & 2.76 & - \\
\hline
\end{tabular}

TS: total solid content; VS: volatile solid.

\subsection{Experiment Method}

The conical bottle of $2000 \mathrm{~mL}$ sealed by rubber plug [17] was used as biogas fermentation device, and the $1500 \mathrm{~mL}$ gas collecting bottle and $2500 \mathrm{~mL}$ beaker were used as gas collecting device.

The biogas fermentation was performed in Erlenmeyer flask which was closed with suitable rubber plug. The total volume and working volume of the bottles were $2000 \mathrm{~mL}$ and $1500 \mathrm{~mL}$. The gas collecting device was composed of $1500 \mathrm{~mL}$ gas collecting bottle and $2000 \mathrm{~mL}$ beaker. The biogas volume was measured based on the downward displacement of water. The specific device is shown in the Figure 1.

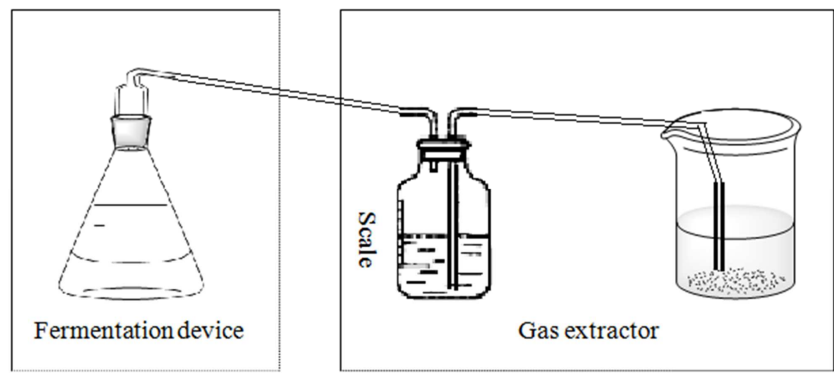

Figure 1. Biogas fermentation device.

\subsubsection{The Method of Temperatures' Influence on Biogas Fermentation of Distillers' Grains}

In all of the three $2000 \mathrm{~mL}$ conical bottles, $299 \mathrm{~g}$ distiller's grains and $312 \mathrm{~mL}$ inoculum were added respectively, and then the tap water was added to the $1500 \mathrm{~mL}$, and the mixture was stirred evenly, that is, the TS mass of the distiller's grains was $3.3 \%$ of the fermentation broth. The TS mass of the inoculum was $1.5 \%$ of the fermentation broth. Before fermentation, the $\mathrm{pH}$ of the fermentation broth was adjusted to about 8.5 with the $\mathrm{NaOH}$ solution of $1 \mathrm{~mol} / \mathrm{L}$, and the three fermentation bottles were placed at room temperature $25^{\circ} \mathrm{C}$ and $38^{\circ} \mathrm{C}$ respectively. A comparative experiment of biogas fermentation was carried out in a shaking bed at high temperature $55^{\circ} \mathrm{C}$. In each group, three groups of parallel experiments were made, and a blank experiment was carried out with the fermentation broth of only the inoculum and the tap water

\subsubsection{The Method of Different Feedstock TS Influence on Biogas Fermentation}

In the six 2000mL conical bottles, $227 \mathrm{~g} / 272 \mathrm{~g} / 299 \mathrm{~g} / 317 \mathrm{~g}$ / 317g / 317g / 363g / 453g distiller's grains were added respectively to $312 \mathrm{~mL}$ inoculum, and then added tap water to $1500 \mathrm{~mL}$, the TS quality of the distiller's grains was $2.5 \%$, $3.0 \%, 3.3 \%, 3.5 \%, 4.0 \%, 5.0 \%$, respectively. The mass ratio of the TS of the inoculum to the quality of the fermentation liquor is $1.5 \%$.

Before fermentation, the fermentation broth $\mathrm{pH}$ in each fermentation bottle was adjusted to about 8.5 with the $\mathrm{NaOH}$ solution of $1 \mathrm{~mol} / \mathrm{L}$. A comparative experiment of biogas fermentation was carried out in a shaking bed with high temperature of $55^{\circ} \mathrm{C}$. Each group was performed in two replicates. All the digesters were placed in three constant-temperature shakers and blank experiments were done with fermentation broth with only inoculum and tap water.

\subsubsection{The Method of Different Inocula Amount Influence on Biogas Fermentation of Distillers' Grains}

There were five treatments in the experiment, and the inoculum concentrations in each treatment were respectively $0.5 \%$. $1.0 \%$. $1.5 \%$. 2.0\%. 2.5\%. The TS concentration of distillers' grains was $3.3 \%$. The fermentation temperature was $55^{\circ} \mathrm{C}$. The $\mathrm{pH}$ of liquid was adjusted to about 8.5 by sodium hydroxide solution at $1 \mathrm{M}$ (mol) concentration. The fermentation experiment were carried out in shaking table. Each treatment was arranged two parallel experiments. A blank experiment was carried out with the fermentation broth containing only inoculum and tap water.

\subsubsection{The Method for Influence of Different pH on Biogas Fermentation of Distillers' Grains}

There were two groups in the experiment. The inoculum concentrations in each group were $1.5 \%$ and the TS concentrations of the feedstock were $3.3 \%$. The $\mathrm{pH}$ of one group was adjusted to about 8.5 by sodium hydroxide solution at $1 \mathrm{M}(\mathrm{mol})$ concentration. The other one remained the original $\mathrm{pH}$. The fermentation temperature was $55^{\circ} \mathrm{C}$. Each group was performed in two replicates. All the digesters were placed in three constant-temperature shakers and a blank experiment was done with only inoculum and tap water.

\subsection{Analytical Methods}

Daily biogas production and cumulative biogas production were obtained by downward displacement of water. The composition of the biogas was determined with a gas chromatography (GC1120). The total solid (TS) and volatile solid (VS) were determined according to standard methods. Total carbon was measured by potassium dichromate method, total nitrogen was measured by Kjeldahl method. the contents of hemicellulose, cellulose and lignin were determined with an automatic fiber analyzer. The biogas production period was calculated at $95 \%$ of the total biogas production and the $\mathrm{pH}$ value was determined with a precision $\mathrm{pH}$ acidity meter. 


\section{Results and Discussion}

\subsection{Effect of Temperature on Biogas Fermentation of Distillers' Grains}

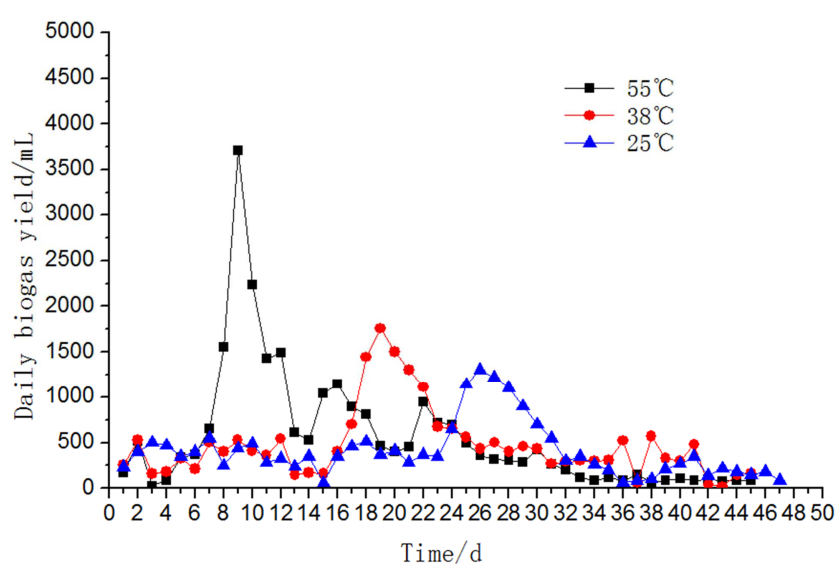

Figure 2. Daily biogas yield of different temperature.

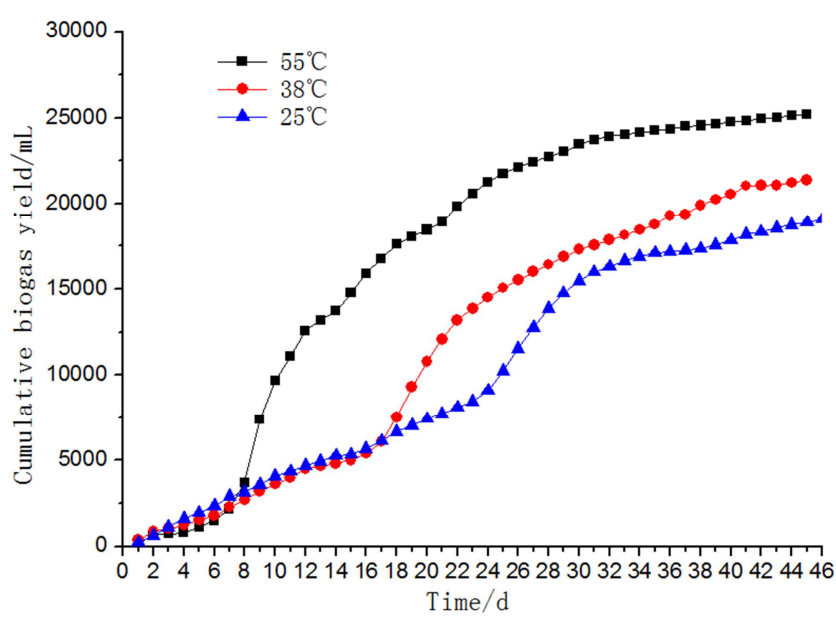

Figure 3. Cumulative biogas yield of different temperature.

Figure 2 and Figure 3 are daily biogas yield chart and cumulative biogas production chart of distillers' grains at three temperatures. The results showed that on the first day of fermentation, the distillers' grains all entered the biogas production stage of the three groups. It may be related to the process of ethanol production. The distillers' grains had went through a preliminary fermentation during the process of ethanol production. In this process, the encapsulation of cellulose, hemicellulose and lignin in the distiller's grains was decomposed initially, and produced more easily degradable components and small molecular substances such as carbohydrates, organic acids and alcohols. The $\mathrm{C} / \mathrm{N}$ rate of distillers grains is 24 which is in the best $\mathrm{C} / \mathrm{N}$ rate range at biogas producing [18]. The maximum daily biogas yield of distiller's grains reached $3710 \mathrm{~mL} / \mathrm{d}$ on the ninth day and the biogas production period was 32 days under the temperature of $55^{\circ} \mathrm{C}$. The maximum daily biogas yield of distiller's grains reached $1760 \mathrm{~mL} / \mathrm{d}$ on the nineteenth day and the biogas production period was 39 days under the temperature of $38^{\circ} \mathrm{C}$. The maximum daily biogas yield of distiller's grains reached $1330 \mathrm{~mL} / \mathrm{d}$ on the twenty-sixth day and the biogas production period was 42 days under the temperature of $25^{\circ} \mathrm{C}$. According to the above datas the peak time and the biogas production period of distillers' grains are shortened with the increasing of temperature. The main reason is that high temperature can accelerate the degradation of lignocellulose. The anaerobic fermentation speed of distiller's grains is fast [10-13]. According to the daily biogas yield chart, with the process of fermentation there were several small peaks of daily biogas production at three fermentation temperatures. It is because that the distiller's grains contain ethanol, amino acids, protein and other components, The time of the hydrolysis, acidification and biogas production of the components are different at the fermentation process. And they have stages, so there are many biogas production peaks [19].

According to the cumulative biogas production data, It can be seen that the cumulative biogas yield of distiller's grains is $25200 \mathrm{~mL}$ and the biogas yield of TS is as high as $509 \mathrm{~mL} / \mathrm{g}$ under the temperature of $55^{\circ} \mathrm{C}$. The cumulative biogas yield of distiller's grains is $21400 \mathrm{~mL}$ and the biogas yield of TS is as high as $432 \mathrm{~mL} / \mathrm{g}$ under the temperature of $38^{\circ} \mathrm{C}$. The cumulative biogas yield of distiller's grains is $19160 \mathrm{~mL}$ and the biogas yield of TS is as high as $387 \mathrm{~mL} / \mathrm{g}$ under the temperature of $25^{\circ} \mathrm{C}$. From above dates It can be seen that with the increase of temperature the cumulative biogas yield and the TS biogas yield of distillers grains are increased. This is because the higher the temperature, the more cellulose is degraded, the more raw materials are available to the microorganism, and the more biogas is produced [20-22]. Therefore, the optimum temperature is $55^{\circ} \mathrm{C}$ at producing biogas about distiller's grains fermentation. The reason why the experiment selected to ferment distillers' grains at high temperature is because the temperature of distiller's grains is higher after distilling and there is a certain amount of heat during the solid-state fermentation of alcohol in the early stage of distiller's grains. If the distiller's grains are directly fermented for biogas after coming out of the distillation tower, This part of the heat can be used to save energy.

\subsection{Effect of Different TS Concentrations of Feedstock on Biogas Fermentation of Distillers' Grains}

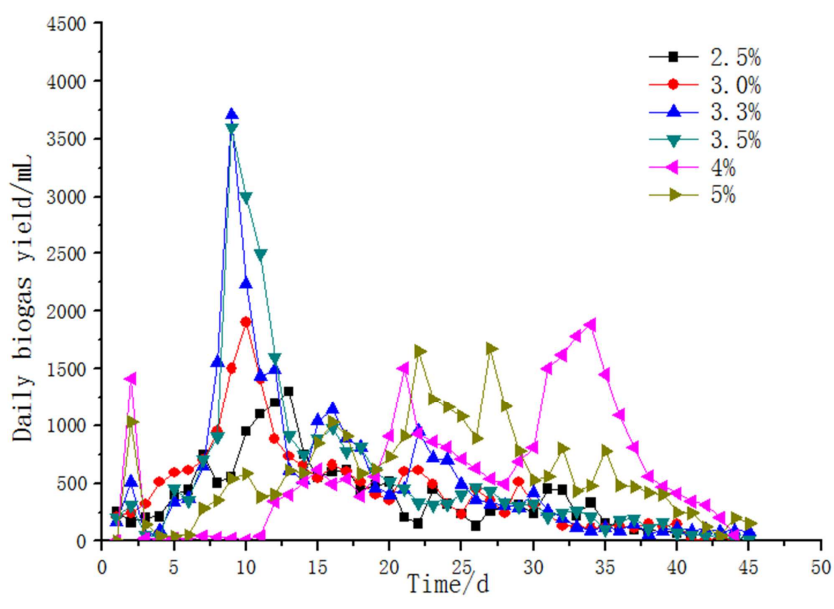

Figure 4. Daily biogas yield of different TS concentrations. 


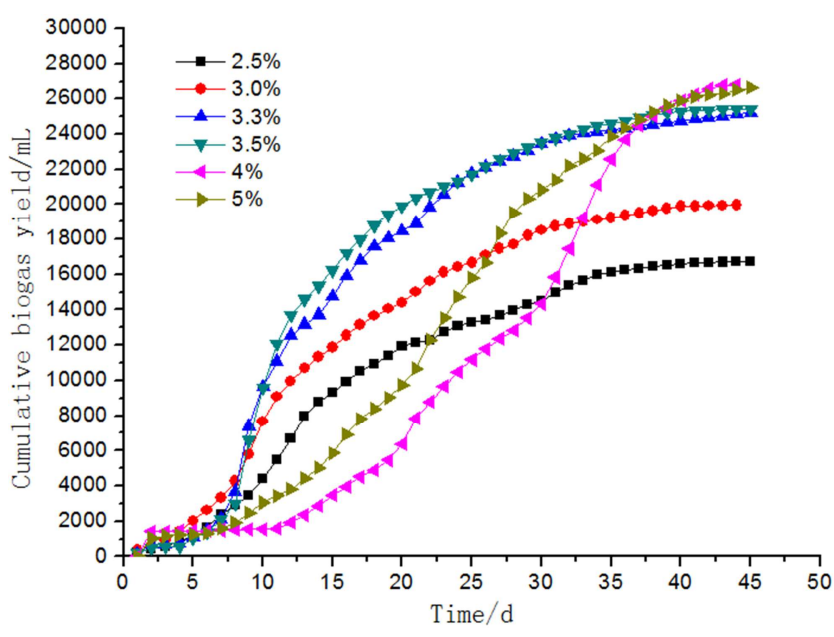

Figure 5. Cumulative biogas yield of different TS concentrations.

Figure 4 and Figure 5 are daily biogas yield chart and cumulative biogas production chart under different TS concentrations of distillers' grains. From the charts it showed that the fermentation entered the biogas production stage on the first day when the TS concentration of distillers grains ranged from $2.5 \%$ to $3.3 \%$. The maximum daily biogas yield reached $1300 \mathrm{~mL} / \mathrm{d}$ on the 13th day, the cumulative biogas yield was $16750 \mathrm{~mL}$, and the biogas yield of TS was $447 \mathrm{~mL} / \mathrm{g}$ when the concentration of TS in distiller's grains was $2.5 \%$. The maximum daily biogas yield reached $1900 \mathrm{~mL} / \mathrm{d}$ on the 11 th day, the cumulative biogas production was $19940 \mathrm{~mL}$, and the biogas yield of TS was $443 \mathrm{~mL} / \mathrm{g}$ at $3.0 \%$ TS concentration. The maximum daily biogas yield reached $3710 \mathrm{~mL} / \mathrm{d}$ on the 9th day, the cumulative biogas production was $25200 \mathrm{~mL}$, and the biogas yield of TS was $509 \mathrm{~mL} / \mathrm{g}$ at $3.3 \%$ TS concentration. The results show that the cumulative biogas production and raw material biogas yield gradually increase with the increasing TS concentration of the feedstock when the TS concentration of distiller's grains rangs from $2.5 \%$ to $3.3 \%$. This is because when the TS concentration of distiller's grains is too low, the amount of organic matter in unit volume is less and the food of the methanogenic bacteria is less. So in a certain range, with the increase of TS concentration of distiller's grains, the cumulative biogas production will increase [23].

When the TS concentration of feedstock ranged from $3.3 \%$ to $5 \%$, the time for the fermentation entering the biogas production stage was longer. The maximum daily biogas yield reached $3900 \mathrm{~mL} / \mathrm{d}$ on the 9th day, the cumulative biogas yield was $25430 \mathrm{~mL}$, and the biogas yield of TS was $484 \mathrm{~mL} / \mathrm{g}$ at $3.5 \%$ TS concentration. The maximum daily biogas yield reached $1030 \mathrm{~mL} / \mathrm{d}$ on the 16th day, the cumulative biogas production was $26810 \mathrm{~mL}$, and the biogas yield of TS was $447 \mathrm{~mL} / \mathrm{g}$ at $4 \%$ TS concentration. The maximum daily biogas yield reached $1500 \mathrm{~mL} / \mathrm{d}$ on the 21th day, the cumulative biogas production was $26640 \mathrm{~mL}$, and the biogas yield of TS was $335 \mathrm{~mL} / \mathrm{g}$ at $5 \%$ TS concentration. As it shows the peak time of biogas production of different treatments delay gradually with the increaseing of TS concentration. The cumulative biogas production increases slowly and the biogas yield of raw materials decreases gradually, when the TS concentration of distiller's grains is higher than $3.3 \%$. It is because when the TS concentration of the feedstock is too high, the rate of acidification exceeds the methane fermentation rate, which is easy to cause the acidification risk to inhibit the activity of methanogens, thereby affecting the biogas production amount [24-25].

According to the above analyses the best TS concentration for biogas fermentation of distiller's grains is $3.3 \%$ at $55^{\circ} \mathrm{C}$, which is lower than that of straw $[16,18]$. It may be that some enzymes, yeasts and other substances enter the distiller's grains during the early fermentation of ethanol, which increases the concentration of degradable components in the distiller's grains, so the effective TS content of the final distiller's grains is higher than other materials [14].

\subsection{Effect of Inoculums Amount on Biogas Fermentation of Distillers' Grains}

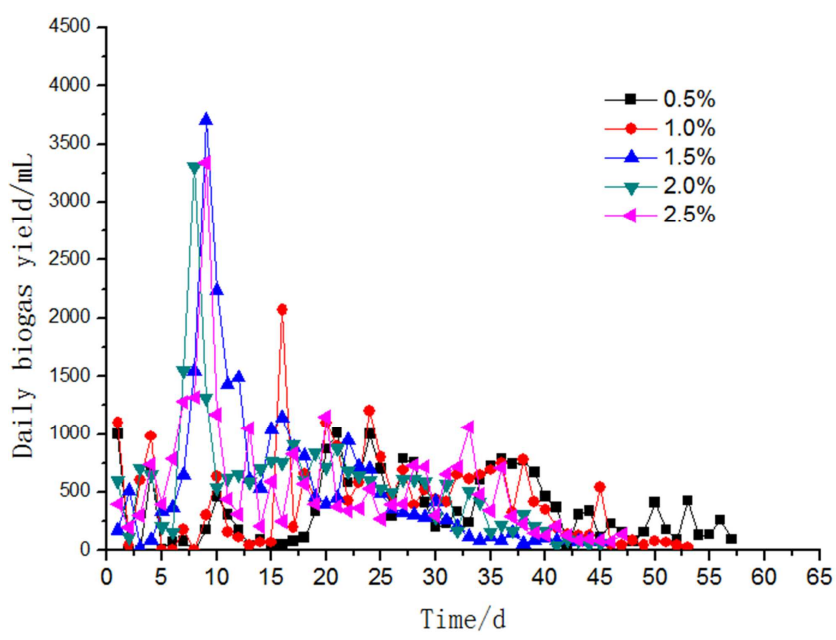

Figure 6. Daily biogas yield of different inoculums amount.

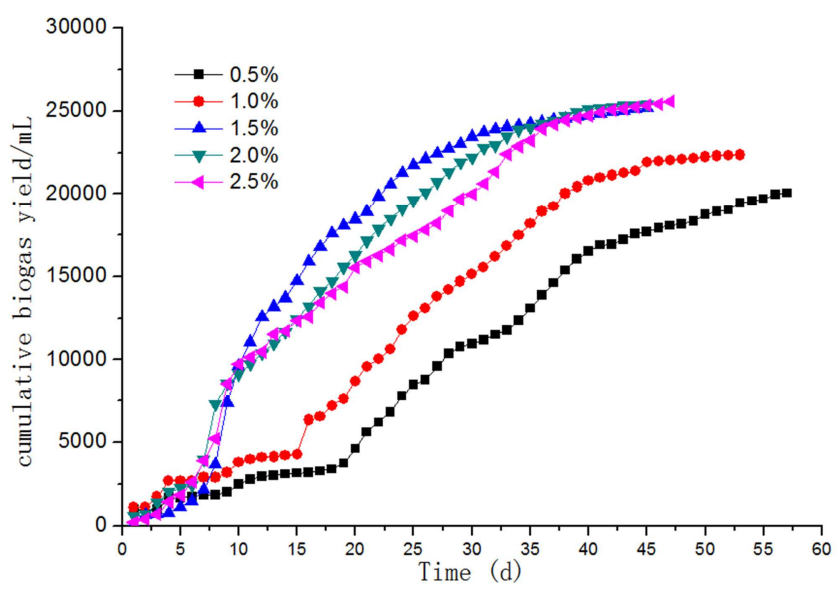

Figure 7. Cumulative biogas yield of different inoculums amount.

Figure 6 and Figure 7 are daily biogas yield chart and cumulative biogas yield chart of distillers' grains at different inoculation amount. From the charts it can be seen that the maximum daily biogas yield reached $1010 \mathrm{~mL} / \mathrm{d}$ on the 21 th day, the cumulative biogas yield was $20060 \mathrm{~mL}$ when the amount of inoculums was $0.5 \%$. When the amount of 
inoculums was $1.0 \%$ the maximum daily biogas yield reached $20700 \mathrm{~mL} / \mathrm{d}$ on the 16th day, the cumulative biogas yield was $22370 \mathrm{~mL}$. The maximum daily biogas yield reached 3710 $\mathrm{mL} / \mathrm{d}$ on the 9 th day, the cumulative biogas yield was $25200 \mathrm{~mL}$ when the amount of inoculums was $1.5 \%$. The results show that the time of the maximum daily biogas yield of distiller's grains is gradually shortened and the cumulative biogas production is gradually added with the increasing of inoculation amount when the amount of inoculums is from $0.5 \%$ to $1.5 \%$. This is because when the inoculation amount is small, the methane bacteria content in the digesters is relatively small, which requires a enrichment process of methanogenic bacteria. So with the increase of inoculation amount, the peak time of biogas production rate is gradually shortened. At this time, the cumulative gas production of distiller's grains is mainly determined by the quantity of methanogenic bacteria, so the cumulative gas production increases gradually with the increase of inoculation amount $[16,19]$.

When the inoculums amount was from $1.5 \%$ to $2.5 \%$, the daily biogas yield of distiller's grains all reached the maximum at about 9 days, which were $3710 \mathrm{~mL}, 3310 \mathrm{~mL}$ and $3340 \mathrm{~mL}$ respectively. The cumulative biogas yield was $25200 \mathrm{~mL}$, $25430 \mathrm{~mL}$ and $25570 \mathrm{~mL}$. It can be seen that when the inoculums amount exceed $1.5 \%$, the maximum daily biogas yield of distiller's grains was no longer advanced, the increase of cumulative biogas production became slow. This is due to the fact that when the inoculums amount reaches a certain value, the enrichment process of methanogenic bacteria is no longer required so the time of the maximum daily biogas yield is basically the same. At this time, the cumulative biogas production is mainly determined by the total amount of organic matter in distiller's grains rather than the amount of methanogenic bacteria [26-28].

In conclusion, the optimum inoculums amount of distiller's grains for biogas fermentation at high temperature was $1.5 \%$. Under this condition it could save inoculums, and the rate of fermentation and cumulative biogas production all reached the best state.

\subsection{Effect of Different pH Value on Biogas Fermentation of Distillers' Grains}

Figure 8 and Figure 9 show the daily biogas production and cumulative biogas production of distiller's grains in two groups of contrastive tests respectively. The figure is observed that if the $\mathrm{pH}$ value of the fermentation is not adjusted, it would drop rapidly from 7.02 to 4.5 on the third day and remain 4.5 until the fifteenth day of fermentation. The average daily biogas yield is only about $200 \mathrm{~mL}$ at this stage. the peak of daily biogas yield appears on the 16th day, It is $1220 \mathrm{~mL} / \mathrm{d}$. The cumulative biogas production is $24930 \mathrm{~mL}$, and the biogas production period is 51 days. It is because that the distiller's grains goes through initial fermentation process during ethanol fermentation. In the initial stage of biogas fermentation, the distiller's grains hydrolyzes rapidly and produces a large number of volatile fat acids and carbon dioxide. The dissolution of volatile fat acids and part of carbon dioxide in the liquid make the $\mathrm{pH}$ value of the fermentation system to drop and acidify.

If the $\mathrm{pH}$ value of the feedstock is adjusted to about 8.5 with sodium hydroxide solution of $1 \mathrm{~mol} / \mathrm{L}$ before fermentation, the feedstock rapidly enters the normal biogas production stage, and the acidification stage only lasts about 3 days. The maximum daily biogas yield is $3710 \mathrm{~mL} / \mathrm{d}$ at 9 th days. The cumulative biogas production is $25200 \mathrm{~mL}$ and the biogas production period is 32 days. The main reason is that alkaline substances ionize $\mathrm{OH}^{-}$when alkaline substance is added into the liquid before fermentation, which neutralize a part of acid and make the fermentation broth rapidly enter the methanogenesis stage.

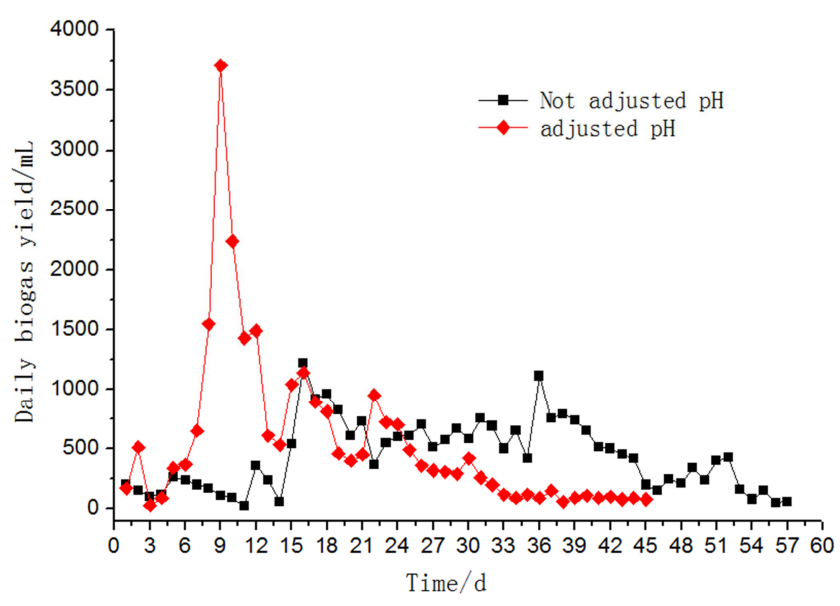

Figure 8. Daily biogas yield of two treatments.

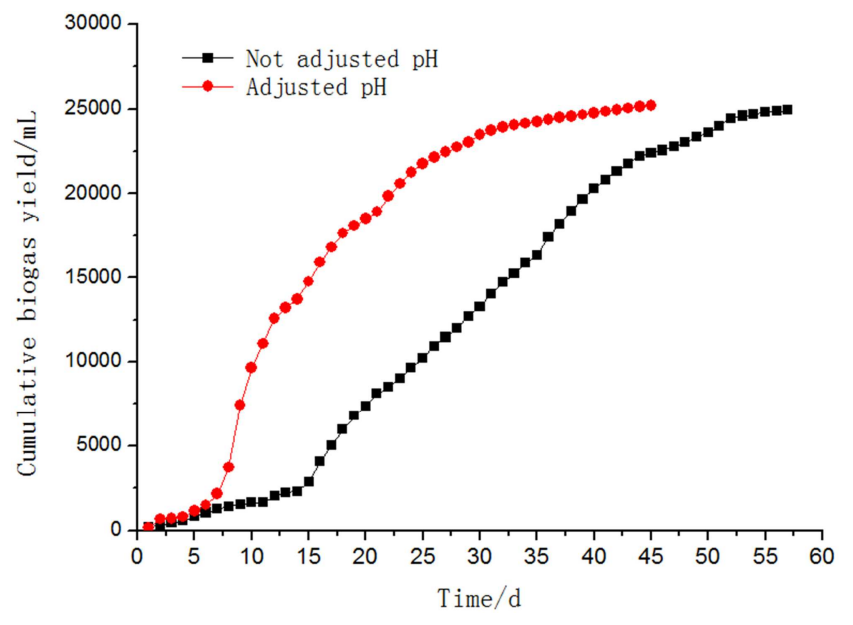

Figure 9. Cumulative biogas production of two treatments.

\section{Conclusion}

The biogas fermentation with distiller's grains as raw materials saves the pretreatment process of raw materials. Among them, carbohydrates, alcohols, organic acids and other easily degradable components and small molecular substances are high. The $\mathrm{C} / \mathrm{N}$ ratio of distiller's grains is about 25 , which is the best $\mathrm{C} / \mathrm{N}$ ratio for biogas fermentation. It doesn' $t$ need to add nitrogen-containing substances such as urea to adjust, which not only reduces the cost, but also accelerates the startup speed of fermentation.

The distiller's grains have a certain amount of heat when 
they come out from the distillation tower. The high temperature biogas fermentation method can make full use of this part of the heat of distiller's grains, thus saving energy consumption and increasing the amount of biogas production and shortening the period of gas production.

The distiller's grains contain some enzymes, yeasts and other substances, which increased the effective fermentation components of distiller's grains. Therefore, the optimal TS concentration for biogas fermentation of distiller's grains at high temperature was $3.3 \%$, which is lower than that of straw.

The acidification stage of distiller's grains can be shortened by adjusting the $\mathrm{pH}$ value of the feedstock before fermentation, and the methane production stage can be quickly entered.

The optimal temperature was $55^{\circ} \mathrm{C}$, the best concentration of distillers' grains was $3.3 \%$, the optimal amount of inocula was $1.5 \%$, and the $\mathrm{pH}$ value should be adjusted before fermentation. Under this condition, the maximum daily biogas production was $3710 \mathrm{~mL} / \mathrm{d}$ and appeared on the 9 th day. The overall length of the fermentation period was $32 \mathrm{~d}$, and the TS biogas yield was up to $509 \mathrm{~mL} / \mathrm{gTS}$.

\section{References}

[1] WANG YAN-fei, QIN XIN-zheng, ZHANG LI-ming. Preliminary study on the screening of energy beet and alcohol production. Sugar Crops of China. NO. 3, 2006, pp 19-21.

[2] JIANG YUE. Optimization of alcohol production from sugar beet fermented in solid-state. Haerbin: Northeast Forestry University, 2007.

[3] SHI SHU-yi, DAI CUI-hong, CHENG DA-you. Screening high temperature tolerant yeast strains and technological optimization of ethanol fermentation of energy beet. Science \& Technology Review. Vol. 29, NO. 3, 2011, pp 71-75.

[4] ZHANG GUO-fu. Research of beet fermentation alcohol craft type by seeping out. Shenyang: Dalian Polytechnic University, 2008.

[5] WANG TAI-tao, ZHAO LONG, ZHANG PAN. Primary experimental on vinasse fermentation for biogas production. China Biogas. Vol. 35, NO. 1, 2017, pp 60-62.

[6] DENG SONG, YANG ZHI-min, HUANG LEI, CHEN YU-cheng, JIANG TAO. Optimization of control conditions in semi-continuous anaerobic fermentation of pig manure and corn stalk. Journal of Agricultural Biotechnology. Vol. 26, NO. 7, 2018, pp 1265-1274.

[7] LIU JIE, LI YUAN-you, ZHENG SHI-mei. Problems and suggestions on processing ethanol with sweet sorghum straw. Journal of Jilin Agricultural Sciences. Vol. 32, NO. 2, 2007, p $62-65$.

[8] SUN QUN, LI JI-hong, FU XING-guo. Hydrothermal process for enzymatic hydrolysis of sweet sorghum bagasse from assf. Acta Energiae Solaris Sinica. Vol. 34, NO. 12, 2013, pp 2073-2077.

[9] HU WEI, CHEN YU. Study on characteristics of biogas production of rice straw mixed with distiller's grains of multiple-grains in anaerobic fermentation. Food and Fermentation Industries. Vol. 40, NO. 12, 2014, pp 15-19.
[10] HUANG PING-hui, ZHANG SHU-ying, QIN QI-rong. The situation demand and countermeasures for natural gas resources in China. Xinjiang Petroleum Geology. Vol. 26, NO. 1, 2005, pp 105-107.

[11] CHEN SI, XIONG CHENG-yong. Re-discussion on $\mathrm{C} / \mathrm{N}$ ratio of straw biogas fermentation. China Biogas. NO. 2, 2009, pp 38-39.

[12] ZHENG ZHAN-yao, YIN FANG, ZHANG WU-di, ZHAO XING-ling, LIU SHI-qing, WU KAI, etal. Experimental study on biogas production potential of Logan shell fermentation. Journal of Anhui Agricultural Science. Vol. 46, NO. 33, 2018, pp 161-164.

[13] CHU LI-li, YANG GAI-he, ZHANG CUI-li. The biogas production efficiency of crop straws at different temperature. Agricultural Research in The Arid Areas. Vol. 26, NO. 2, 2008, p 190-193.

[14] ZHOU YIN-cun, ZHAO XIN-shi, YANG DI, BI SHENG-lei, LU LONG, HU SHOU-zhen, etal. Effect of different wall-breaking pretreatment on biogas production of algae residue. China Biogas. Vol. 36, NO. 1, 2018, pp 26-31.

[15] BAI NA, MEI ZI-li, FU ZHENG-ge. The effects of temperature on anaerobic digestion of three different straws for biogas production China Biogas. Vol. 29, NO. 1, 2011, pp 16-21.

[16] ZHANG CUI-li, YANG GAI-HE, PU DONG-sheng. Effect of temperature on biogas production and fermentation period length from the anaerobic digestion of crop residue. Journal of Agro-environment science. Vol. 27, NO. 5, 2008, pp 2069-2074.

[17] MING WANG, WEN ZHE-li, PENG FEI-li, SHUI PING-yan, YAN LIN-zhang. An alternative parameter to characterize biogas materials: Available carbon-nitrogen ratio. Waste Management. Vol. 62, 2017, pp 76-83.

[18] ZHANG CUI-li. Study on the effect of temperature on characteristic of biogas production for anaerobic digestion. Yangling, China: Northwest A\&F University, 2008.

[19] LI JIN-juan, LIU FANG, FENG JIE. Effect of temperature and TS on biogas yield by anaerobic fermentation of wheat distiller's grains. Liquor-marking Science Technology. NO. 1, 2011, pp 106-109.

[20] WANG DIAN-long, WU BO, AI PING, XIN YA, HE MING-xiong, ZHANG YAN-lin. Effect of Two-step pretreatment on enzymatic hydrolysis and biogas fermentation of anaerobically digested fiber from VFAs production. Transactions of the Chinese Society for Agricultural Machinery. Vol. 49, NO. 3, 2018, pp 322-327.

[21] GUO OU-yan, LI YI-bing, BAI HAO-rui, Effect of temperature on gasification characteristics of chicken feces and crop residue. Journal of Northwest A\&F University. NO. 6, 2009, pp 137-144.

[22] DUO ZI-lin. Effects of total solid concentration at different temperatures on biogas production characteristics of anaerobic fermentation. Yangling, China: Northwest A\&F University, 2010 .

[23] GUO TING, XU SHUAI, LU XIAO-yu. Preliminary study on the biogas fermentation for mixture of straw and potale. Science and Technology of Food Industry. NO. 8, 2010, pp 248-250. 
[24] MU WEI-na, LI YU-cheng, WU CHAO, ZHANG XUE-sheng, WANG NING, GAO ZHAO-hui. Analysis of Microbial community in methane co-fermentation of straw \& blue algae. Journal Microbiology. Vol. 37, NO. 1, 2017, pp 70-77.

[25] HAN MENG-long, ZHU JI-ying, ZHANG GUO-kang. Effect of different inoculums on solid state anaerobic digestion of corn stover. Acta Scientiae Circumstantiae. Vol. 34, NO. 10, 2014, pp 2586-2591.

[26] WANG YAN-jin, HUANG JUN, ZHANG QUAN-guo. Experimental study on biogas and fertilizer co-production of wheat straw dry anaerobic fermentation. Journal of Henan Agricultural University. Vol. 46, NO. 4, 2012, pp 402-405.

[27] MA RU-xia, ZHAO YI-quan, LI JIA-wei, HUO ZHAO-chen, HONG YAN-hua, YAN LAI, etal. The optimization of nitrogen sources in anaerobic digestion of corn stover. Renewable Energy Resource. Vol. 36, NO. 11, 2018, pp 1593-1599.

[28] YUE LING-liu, KAI FENG, HUAN LI. Rapid conversion from food waste to electricity by combining anaerobic fermentation and liquid catalytic fuel cell. Applied Energy. Vol. 1, 2019, pp 395-402. 